\title{
Optimization of the Impeller Geometry for an Automotive Torque Converter Using Response Surface Methodology and Desirability Function
}

\author{
Xiang Chen*, Jie Chen \\ Hasco Powertrain Components Systems (Shanghai) Co., Ltd., Shanghai, China \\ Email: ^Xiang.Chen@hasco-pt.com
}

How to cite this paper: Chen, $X$. and Chen, J. (2020) Optimization of the Impeller Geometry for an Automotive Torque Converter Using Response Surface Methodology and Desirability Function. Open Journal of Applied Sciences, 10, 455-475. https://doi.org/10.4236/ojapps.2020.107032

Received: June 24, 2020

Accepted: July 24, 2020

Published: July 27, 2020

Copyright (c) 2020 by author(s) and Scientific Research Publishing Inc. This work is licensed under the Creative Commons Attribution International License (CC BY 4.0).

http://creativecommons.org/licenses/by/4.0/

\begin{abstract}
Response surface methodology (RSM) based on desirability function approach (DFA) is applied to obtain an optimal design of the impeller geometry for an automotive torque converter. The relative importance of six design parameters including impeller blade number, blade thickness, bias angle, scroll angle, inlet angle and exit angle is investigated using orthogonal design approach. The impeller inlet angle, exit angle and bias angle are found to exert the greatest influence on the overall performance of a torque converter, with two flow area factors being considered, namely $17 \%$ and $20 \%$. Then, RSM together with central composite design (CCD) method is used to in-depth evaluate the interaction effect of the three key parameters on converter performance. The results demonstrate that impeller exit angle has the strongest impact on peak efficiency, with larger angles yielding the most favorable results. The stall torque ratio maximization is attainable with the increase of impeller bias angle and inlet angle together with smaller exit angle. In the end, an optimized design for the impeller geometry is obtained with stall torque ratio and peak efficiency increased by $1.62 \%$ and $1.1 \%$, respectively. The new optimization method can be used as a reference for performance enhancement in the design process of impeller geometry for an automotive torque converter.
\end{abstract}

\section{Keywords}

Automotive Torque Converter, Response Surface Methodology, Desirability Function Approach, Central Composite Design, Optimization

\section{Introduction}

Torque converters are widely used in vehicle power transmission systems and 
transfer the torque and power from engine to transmission by the hydraulic operation of transmission oil. Despite of its ability to provide good acceleration performance and absorb excessive vibration, its mechanical efficiency is relatively low. Nowadays, a few new techniques are in use to overcome the low efficiency. The application of the locking clutch of the turbine to the impeller and the optimized design of shape of torus and blades to enhance the hydraulic performance are the two representative methods. The first technique is very effective at the wider range of vehicle speed, but not easy to obtain an optimized shape since a large number of design parameters are involved. Typically, several torque converters are designed and tested by computational fluid dynamics (CFD) and experiment until the target performance is met [1]. In an automatic transmission, the output torque and power of the engine is imparted to the transmission oil by the impeller of the torque converter. The impeller provides the pressure rise and increases the angular momentum of the oil through the rotation and the flow turning [2]. Therefore, it is very important to understand the influence of impeller geometrical parameters on performance characteristics of a torque converter. This knowledge will greatly help designers to improve the torque converter performance.

It is generally been accepted that while the accuracy of CFD analyses has not yet achieved a level that is equivalent to experimental techniques, its ability to correctly predict the direction of any changes is reliable [3]. In recent years, CFD has been widely used in turbomachinery design and optimization. Rutter et al. [4] investigated the hydraulic performance of a centrifugal pump within the electrical submersible pump (ESP) unit in single-phase flow using CFD technique. Zhao, et al. [5] optimized a double-channel pump's impeller by combined using CFD, multi-objective genetic algorithm (MOGA) and artificial neural networks (ANN). Shojaeefard, et al. [6], and Bellary, et al. [7], improved the performance of a centrifugal pump impeller based on CFD simulations. Hur, et al. [8] analyzed the flow and performance of a partially-charged water retarder by CFD. Many researchers have also studied the flows in torque converters by using CFD codes employing various methods [9] [10] [11]. In order to improve the converter performance, it is required to obtain detailed understanding and relationship between the governing parameter and its effect on the performance, including efficiency, torque ratio and the input capacity factor. Kubo, et al. [12] analyzed the effects of the turbine bias angle and the impeller flow passage contraction ratio on the internal flow characteristics and the occurrence of loss. Shin, et al. [13] investigate the effect of the flow section area, flow rate, impeller blade angle and scroll angle of impeller and turbine on the performance of a torque converter. The analytical and numerical results obtained a refined relationship between geometry and performance. Shin, et al. [14] [15] investigated the effect of reactor blade geometry with varying thickness ratios, scroll angles and slot angles on the performance of a torque converter. However, the existing studies are limited to investigate the influence of only one or two geometrical para- 
meters individually each time, and reports in the literature regarding their combinations effect on the torque converter performance characteristics can hardly be found.

The traditional one-factor-at-a-time approach has been widely used for evaluation or optimization of these parameters [16] [17] [18]. The major disadvantage of this approach is that it fails to consider any possible interaction between factors, and therefore it may lead to misinterpretation of results. However, design of experiments (DOE) and CCD statistical approaches enable the simultaneous study of several factors and assessment of their statistical significance, as well as the evaluation of interaction effects. DOE method is widely used to find the importance level of the design parameters with respect to the optimization target and obtain the best combination of design variables. Park, et al. [19] studied a methane-fueled gas engine generator with addition of hydrogen using DOE method. Wu, et al. [20] studied the influence of volute geometrical variations on hydrodynamic characteristics of a high speed circulator pump by using CFD technology and DOE method. Taghavifar, et al. [21] applied DOE evaluation to introduce the optimum injection strategy-chamber geometry of diesel engine. CCD method is widely applied to evaluate the interaction effect and explore the optimum combination of key parameters. Sagbas [22] optimized ball burnishing process using rotatable central composite design (CCD) together with desirability function approach. Hatami, et al. [23] applied CCD approach to obtain an optimal design of the vane geometry for a variable geometry turbine. Although several studies [24] [25] [26] were reported using various methods to optimize torque converters, application of DOE combined with CCD to optimize a torque converter is scarce.

In this present paper, the main objective is to improve the overall performance of automotive torque converters by means of impeller geometry optimization using DOE and CCD methods. A new parametric geometric design method of impeller is proposed by using parametric equations and Creo software. A DOE array is used to reduce the number of analyses required at each flow area factor, with two area factors being investigated, namely $17 \%$ and $20 \%$. The DOE post-processing analysis is also used to rank the relative importance of the geometric parameters for both area factors. Then, the CCD method is applied to in-depth evaluate the interaction effect of the three most important parameters and the optimization is done to have the best overall performance of a torque converter.

\section{Parametric Model of Impeller}

\subsection{Torus Design}

The impeller parametric design starts with the definition of the torus shape. Various design parameters including active diameter, aspect ratio and two arc radii are needed to determine the shell profile of an automotive torque converter torus. As the flow area in the circular path, in the proposed torque converter 
model, is assumed constant, only the design parameter area factor $f_{\mathrm{a}}$ is used to determine the design path and core of torus. Consequently, by defining the impeller inlet radius $R_{1}$ and outlet radius $R_{2}$, along with the shell and core, the torus profile of impeller can be obtained as shown in Figure 1.

\subsection{Blade Design}

Each impeller blade profile (Figure 3(c)) is formed by a three dimensional (3D) curve of the shell and a $3 \mathrm{D}$ curve of the core. The $3 \mathrm{D}$ curve can be calculated from the torus and a two dimensional (2D) design curve using conformal transformation principle. Figure 2 shows the schematic representation of a $2 \mathrm{D}$ design curve. With the origin at the starting point of the curve, the coordinate of $P_{0}$ is $(0,0)$. The curve expression can be written with the following equation:

$$
A x^{2}+B y^{2}+C x+D y+E x y=0,
$$

where $A, B, C, D$ and $E$ are the coefficients of the variables. It should be noted that the value of $D$ is 1.0 and the parametric equation of the $2 \mathrm{D}$ design curve can be obtained as

$$
\begin{gathered}
A x_{1}^{2}+B y_{1}^{2}+C x_{1}+y_{1}+E x_{1} y_{1}=0 \\
A x_{2}^{2}+B y_{2}^{2}+C x_{2}+y_{2}+E x_{2} y_{2}=0 \\
\tan \left(\alpha_{2}-90\right)+C=0 \\
\left(E x_{2}+2 B y_{2}+1\right) \tan \left(\alpha_{1}-90\right)+2 A x_{2}+E y_{2}+C=0,
\end{gathered}
$$

where $\alpha_{1}$ is the exit angle of impeller, and $\alpha_{2}$ is the inlet angle of impeller. In the present study, four design parameters including exit angle $\alpha_{1}$, inlet angle $\alpha_{2}$, offset size $d$, and conic factor $f_{\mathrm{c}}$ are provided to calculate the $2 \mathrm{D}$ design curve. The coordinates of $P_{c}$ and $P_{1}$ can be obtained as

$$
\begin{gathered}
y_{c}=x_{c} \tan \left(\alpha_{2}-90\right), \\
y_{c}=y_{2}-\left(x_{2}-x_{c}\right) \tan \left(\alpha_{1}-90\right), \\
x_{1}=x_{2} / 2+\left(x_{c}-x_{2} / 2\right) f_{c}, \\
y_{1}=y_{2} / 2+\left(y_{c}-y_{2} / 2\right) f_{c},
\end{gathered}
$$

where $P_{c}\left(x_{c}, y_{c}\right)$ is the intersection of the two tangent lines that across the curve's starting and ending points, respectively (Figure 2). According to the definition of $2 \mathrm{D}$ design curve, $x_{2}$ value and $y_{2}$ value equal to the length of torus $l$ and offset size $d$, respectively.

The $2 \mathrm{D}$ design curve can be easily constructed by having the torus and the four design parameters defined. After the definition of $3 \mathrm{D}$ curves of shell and core, another design parameter bias angle $\beta$ is used to obtain the blade profile. Given the impeller blades are constant-thickness stamped sheet metal, the blade thickness $t$ is defined. Once the torus shape and five-blade design parameters including exit angle $\alpha_{1}$, inlet angle $\alpha_{2}$, offset size $d$, conic factor $f_{\mathrm{c}}$, bias angle $\beta$ and blade thickness $t$ are determined, the basic blade geometry of impeller is 
generated by means of parametric equations and Creo software. The schematic representation of the construction of impeller blade is shown in Figure 3.

After the definition of the torus and a blade, the construction of the whole impeller geometry is easy and is based on the rotation of the generic blade around the axis; for doing so the number of blades $z$ should be provided by the user. The completed impeller parametric geometry is shown in Figure 4. The design parameters considered for the parametric study are shown in Table 1, provided that the torus of impeller is determined.

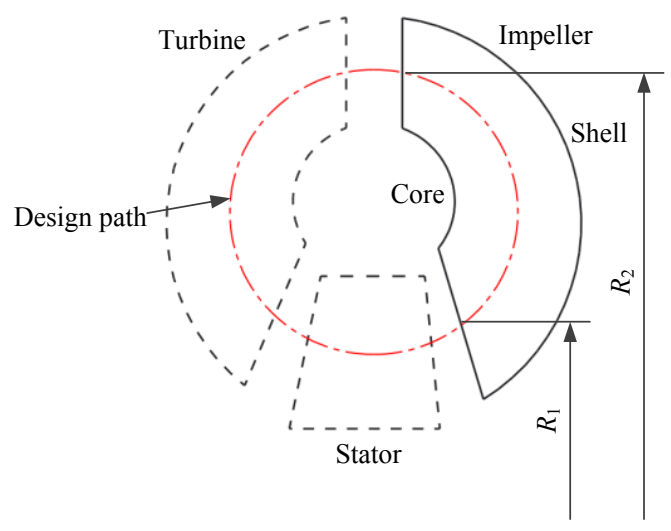

Figure 1. Torus profile of impeller.

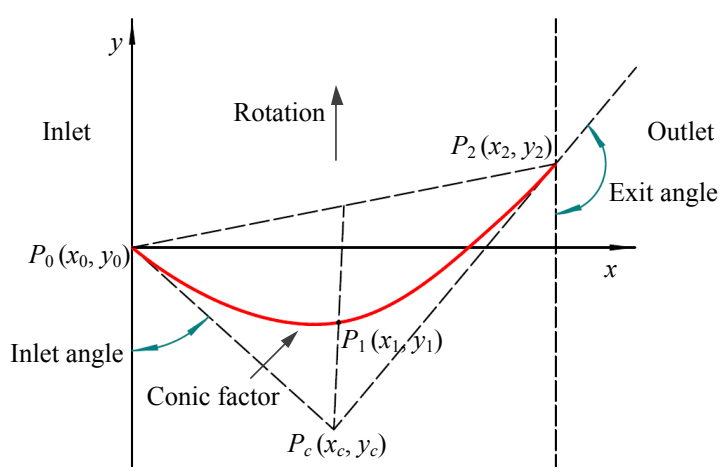

Figure 2. Schematic representation of 2D design curve.

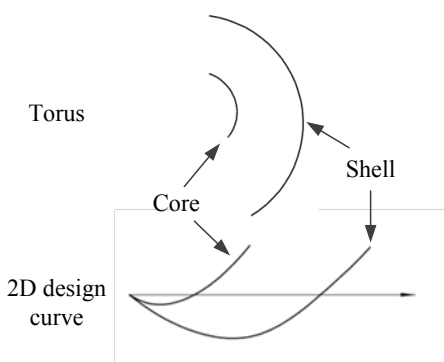

(a)

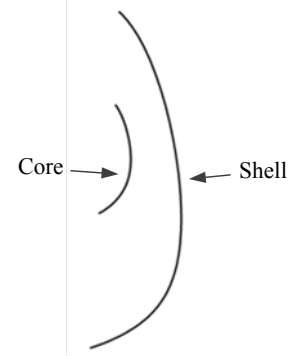

(b)

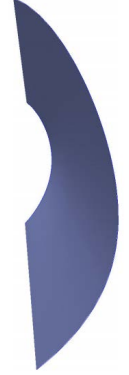

(c)

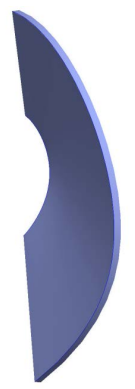

(d)

Figure 3. Schematic representation of the construction of impeller blade: (a) 2D design curve for impeller blade, (b) 3D curve of impeller, (c) blade profile of impeller, (d) blade geometry of impeller. 


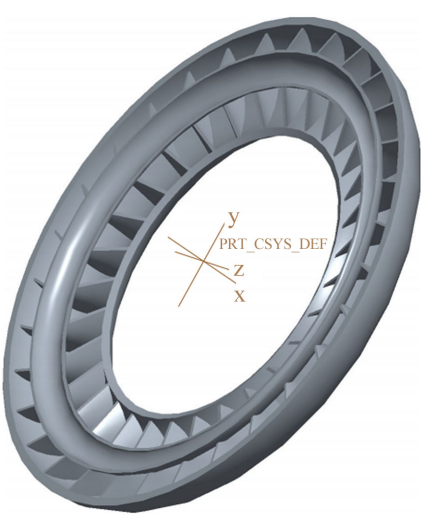

Figure 4. Impeller parametric geometry.

Table 1. Parameters of impeller.

\begin{tabular}{ccc}
\hline No. & Description & Parameter \\
\hline 1 & Exit angle of impeller at shell $\left(^{\circ}\right)$ & $\alpha_{\mathrm{s} 1}$ \\
2 & Inlet angle of impeller at shell $\left(^{\circ}\right)$ & $\alpha_{\mathrm{s} 2}$ \\
3 & Conic factor of impeller blade at shell & $f_{\mathrm{cs}}$ \\
4 & Offset size of impeller blade at shell $(\mathrm{mm})$ & $d_{\mathrm{s}}$ \\
5 & Exit angle of impeller at core $\left(^{\circ}\right)$ & $\alpha_{\mathrm{c} 1}$ \\
6 & Inlet angle of impeller at core $\left(^{\circ}\right)$ & $\alpha_{\mathrm{c} 2}$ \\
7 & Conic factor of impeller blade at core & $f_{\mathrm{cc}}$ \\
8 & Offset size of impeller blade at core $(\mathrm{mm})$ & $d_{\mathrm{c}}$ \\
9 & Bias angle of impeller $\left({ }^{\circ}\right)$ & $\beta$ \\
10 & Blade number of impeller & $Z$ \\
11 & Blade thickness of impeller $(\mathrm{mm})$ & $t$ \\
\hline
\end{tabular}

\section{Model Verification}

\subsection{Computational Approach}

An automotive torque converter is selected as a reference to generate the parametric model. The reference torque converter has an active diameter of $250 \mathrm{~mm}$ and the number of blades in the impeller, turbine, and stator are 31,29, and 21, respectively. STAR-CCM + software is used to generate the computational mesh and perform the internal flow calculations in an appropriate way. The computational mesh is given in Figure 5 where only one blade passage is modeled for each element to illustrate the mesh distribution in the computational field when approximately 111,000 grid cells in total are used. The polyhedral cells with five prism layers are used on the model. The leakage between the elements and also between an element and the core flow are disregarded. A cyclic boundary condition is imposed on both peripheral boundaries outside a blade passage. A no-slip wall boundary condition is also imposed on all the walls bounding the domain, with a spin applied as necessary. The interfaces between elements have been 
handled by using the mixing plane method. A second-order upwind differencing scheme is utilized and the SST $k-w$ model is also used for the turbulence. Steady state simulations are performed for a range of speed ratios from 0.0 to 0.9 while maintaining an impeller speed of $2000 \mathrm{rpm}$.

\subsection{Comparison between Simulation and Experimental Results}

Figure 6 compares the measured and calculated overall performance including efficiency $\eta$, torque ratio $T r$, and impeller torque factor $\lambda_{\mathrm{I}}$ for the parametric model of the torque converter. As indicated here, the tendencies of the experimental data correlated relatively well with the calculated results, confirming that the parametric model and computational method are valid in general. It is of note that the CFD underestimates the impeller torque factor $\lambda_{\mathrm{I}}$ at low speed ratios. The discrepancy between measurements and calculations are reasonable because of the overestimated incidence losses at low speed ratios.

\section{Design of Experiments (DOE)}

\subsection{Influence of Flow Area}

When the circuit size is determined with satisfying the performance requirements, the flow cross-section can be determined with a rule of thumb that the flow area is uniform throughout the blades. In the present study, three toque converter parametric models with different flow areas are designed and simulated to investigate the effects of flow area on their overall performance including efficiency and impeller torque factor. For comparison, the flow area is altered to $17 \%, 20 \%$, and $23 \%$ of area of a circle represented by the converter diameter $\left(f_{\mathrm{a}}=\right.$ $17 \%, 20 \%$, and $23 \%$ ). The design parameters are unchanged as much as possible except the area factors and simulation models with varying area factors are shown in Figure 7.

In Figure 8, the performance analysis shows the significant increases of impeller torque factor with the flow area increases, whereas efficiency calculation does not show significant increase as shown in Figure 9. It can be concluded that the impeller torque factor is more sensitive than efficiency to the torque converter's flow area.

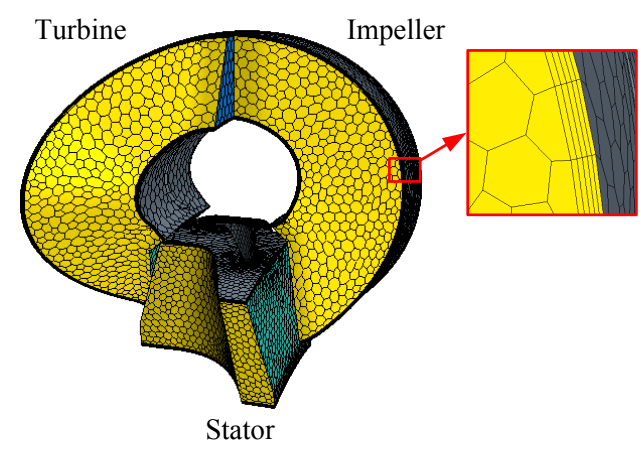

Figure 5. Torque converter grid model. 


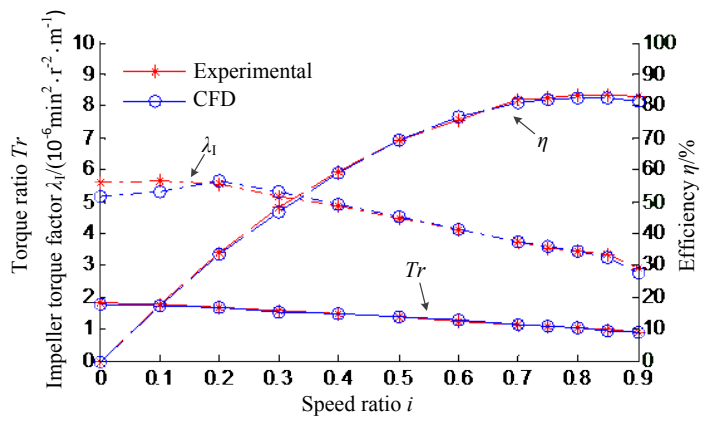

Figure 6. Comparison of the CFD calculation analysis with experimental results.

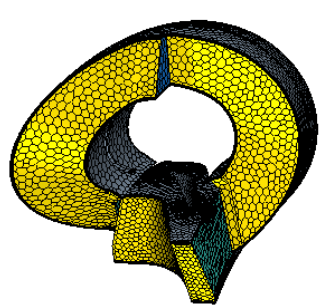

(a)

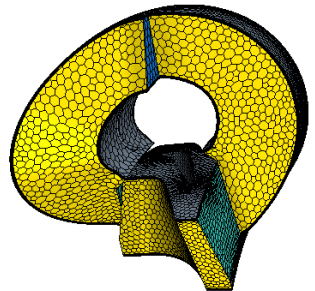

(b)

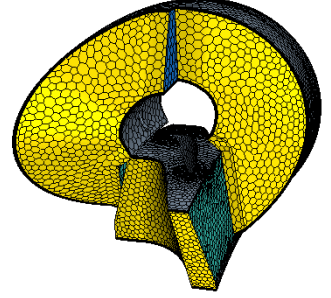

(c)

Figure 7. Simulation models with varying area factors: (a) $f_{\mathrm{a}}=17 \%$, (b) $f_{\mathrm{a}}=$ $20 \%$, and (c) $f_{\mathrm{a}}=23 \%$.

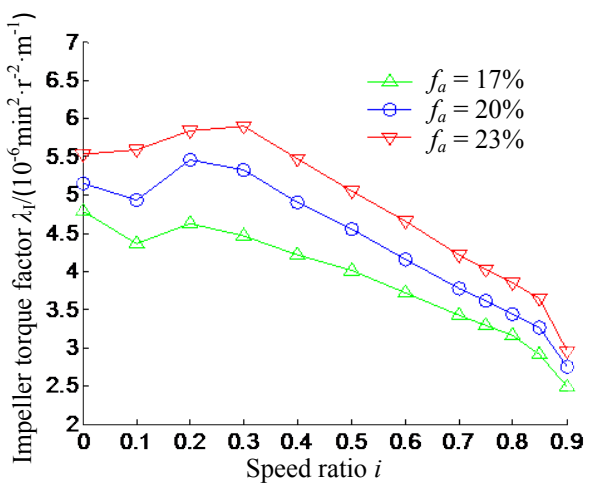

Figure 8. Effects of flow area on impeller torque factor of torque converters.

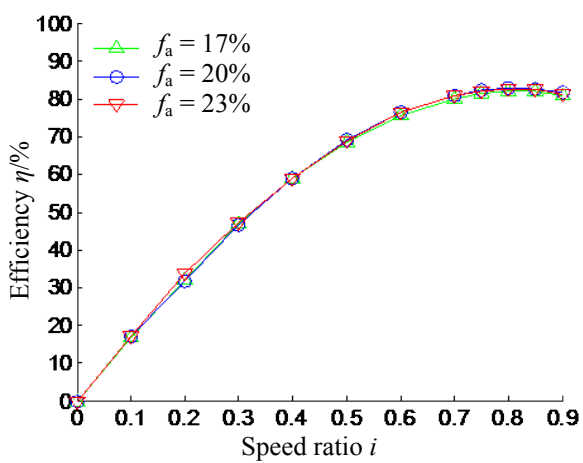

Figure 9. Effects of flow area on efficiency of torque converters. 


\subsection{Factors and Levels in DOE}

DOE is a collection of mathematical and statistical techniques to reduce the number of experiments in order to find the effect of parameters affecting a response in a process, thereby aiming for a reduction in both costs and time [27] [28] [29]. A DOE method sets out configurations (or arrangements) to be conducted using an appropriate orthogonal array; the terminology used in these arrays includes "factors" - an item that is to be varied during the simulations, "level"-the number of times a factor is to be varied during the simulations and "configuration number" - the number of simulations that are required to be run to complete the analysis [30]. The selection of an appropriate DOE array is dependent on the number of factors and the levels of the factors to be analyzed. As mentioned above, 11 design parameters are used to obtain an impeller parametric model. Blade scroll angle $\gamma$ is introduced as another design parameter to investigate the effect of the impeller geometry on the performance of a torque converter. The scroll angle is defined as the angle between the two planes containing the intersection of the design path and the entering and leaving edges of the blade when that blade does not lie in one axial plane. Impeller blades with varying scroll angles are shown in Figure 10.

The scroll angle can be determined by four design parameters including exit angle $\alpha_{1}$, inlet angle $\alpha_{2}$, conic factor $f_{\mathrm{c}}$, and offset size $d$, provided that the torus is defined. Matlab software is used to develop a simple-to-use GUI to calculate scroll angle as shown in Figure 11.

The blade scroll angles at shell and core can be represented by the blade scroll angle on the design path. Similarly, the inlet angles and exit angles at shell and core can be represented by the inlet angle and exit angle on the design path. Finally, the 11 design parameters of impeller are translated into 6 parameters including exit angle $\alpha_{1}$, inlet angle $\alpha_{2}$, scroll angle $\gamma$, bias angle $\beta$, blade thickness $t$, and blade number $z$. The selected factors and levels in DOE are listed in Table 2. The underline sign in the table indicates the base value of impeller design parameters.

\subsection{DOE Evaluation}

For this paper, six main geometrical parameters mentioned above are selected as design variables (factors) and five different values (levels) are assigned for each design parameter. So $25\left(L_{25}\left[5^{6}\right]\right)$ configurations with different combinations are generated for DOE. Stall torque ratio $T r_{0}$ and peak efficiency $\eta^{*}$ are used as the dynamic characteristic and economic characteristic, respectively, to evaluate the performance of torque converters. Two area factors including $17 \%$ and $20 \%$ are considered. The final design matrix in DOE is presented in Table 3 along with the responses predicted by CFD.

One aspect of the DOE method is utilized response averages, calculated for each response and area factor in relation to a specific geometry parameter variable, to provide detail relating to the influence of the geometric factors on the 
performance of a torque converter. For example, to calculate the response averages relating to the 27 blade number, the average of the stall torque ratio and peak efficiency would be calculated from case number 1, 2, 3, 4 and 5. The calculated response average values for each level and for all parameters are shown for each area factor in Table 4, Table 5.
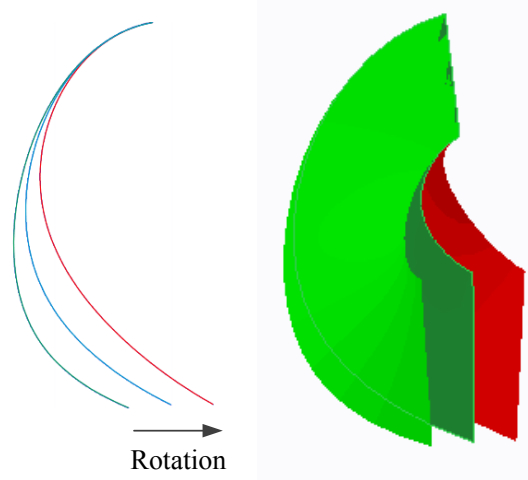

Figure 10. Impeller blades with varying scroll angles.

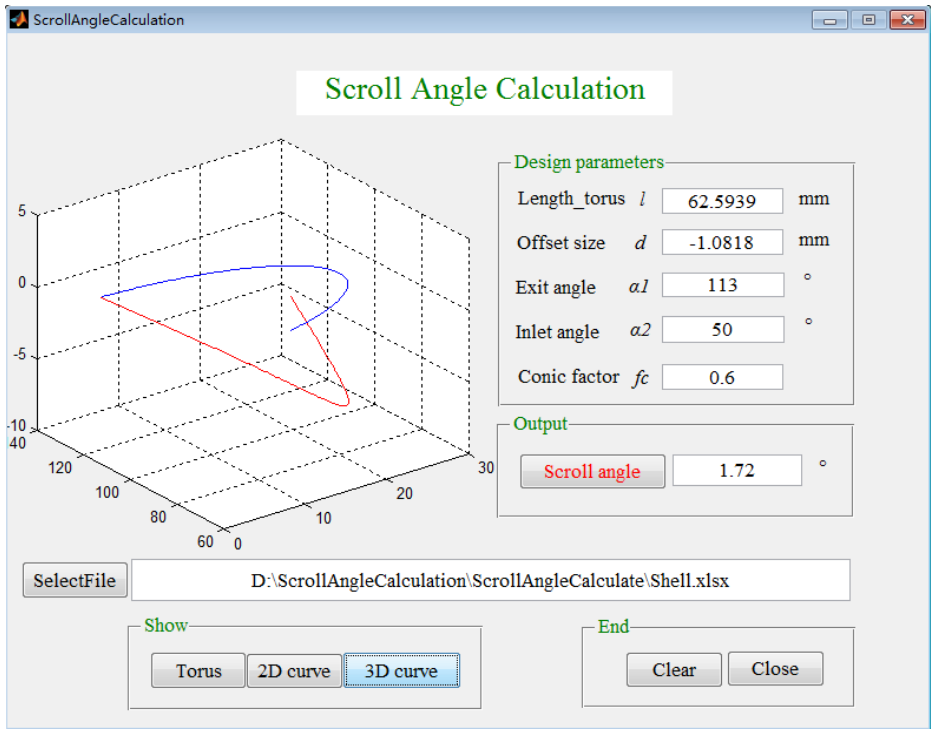

Figure 11. GUI interface used for scroll angle calculation.

Table 2. Factors and levels in DOE.

\begin{tabular}{cccccc}
\hline Factors & Levels & & & & \\
\hline & 1 & 2 & 3 & 4 & 5 \\
$Z$ & 27 & 29 & $\underline{31}$ & 33 & 35 \\
$t /(\mathrm{mm})$ & 0.9 & $\underline{1.0}$ & 1.1 & 1.2 & 1.3 \\
$\beta /\left(^{\circ}\right)$ & -1.5 & $\underline{0}$ & 1.5 & 3 & 4.5 \\
$\gamma /\left(^{\circ}\right)$ & -0.28 & $\underline{0.72}$ & 1.72 & 2.72 & 3.72 \\
$\alpha_{1} /\left(^{\circ}\right)$ & 103 & 108 & $\underline{113}$ & 118 & 123 \\
$\alpha_{2} /\left(^{\circ}\right)$ & 45 & $\underline{50}$ & 55 & 60 & 65 \\
\hline
\end{tabular}


Table 3. Design matrix and results in DOE.

\begin{tabular}{|c|c|c|c|c|c|c|c|c|c|c|}
\hline \multirow{3}{*}{ Case number } & \multicolumn{6}{|c|}{ Factors } & \multicolumn{4}{|c|}{ Responses } \\
\hline & \multirow{2}{*}{$z$} & \multirow{2}{*}{$t /(\mathrm{mm})$} & \multirow{2}{*}{$\beta /\left(^{\circ}\right)$} & \multirow{2}{*}{$\gamma /\left(^{\circ}\right)$} & \multirow{2}{*}{$\alpha_{1} /\left(^{\circ}\right)$} & \multirow{2}{*}{$\alpha_{2} /\left(^{\circ}\right)$} & \multicolumn{2}{|c|}{$f_{\mathrm{a}}=17 \%$} & \multicolumn{2}{|c|}{$f_{\mathrm{a}}=20 \%$} \\
\hline & & & & & & & $T r_{0}$ & $\eta^{*} /(\%)$ & $T r_{0}$ & $\eta^{*} /(\%)$ \\
\hline 1 & 27 & 0.9 & -1.5 & -0.28 & 103 & 45 & 1.715232 & 79.86550 & 1.809260 & 78.50370 \\
\hline 2 & 27 & 1.0 & 0 & 0.72 & 108 & 50 & 1.702694 & 80.23373 & 1.810344 & 80.11081 \\
\hline 3 & 27 & 1.1 & 1.5 & 1.72 & 113 & 55 & 1.748850 & 81.29262 & 1.866738 & 82.27918 \\
\hline 4 & 27 & 1.2 & 3 & 2.72 & 118 & 60 & 1.769172 & 80.97452 & 1.880240 & 81.48316 \\
\hline 5 & 27 & 1.3 & 4.5 & 3.72 & 103 & 65 & 1.798510 & 79.84045 & 1.918926 & 79.15727 \\
\hline 6 & 29 & 0.9 & 0 & 1.72 & 118 & 65 & 1.744180 & 81.48267 & 1.831391 & 81.16512 \\
\hline 7 & 29 & 1.0 & 1.5 & 2.72 & 123 & 45 & 1.713947 & 79.86550 & 1.817788 & 84.49367 \\
\hline 8 & 29 & 1.1 & 3 & 3.72 & 103 & 50 & 1.795316 & 80.23373 & 1.865114 & 79.05313 \\
\hline 9 & 29 & 1.2 & 4.5 & -0.28 & 108 & 55 & 1.777395 & 81.29262 & 1.897089 & 80.72167 \\
\hline 10 & 29 & 1.3 & -1.5 & 0.72 & 113 & 60 & 1.693166 & 80.97452 & 1.772419 & 80.65617 \\
\hline 11 & 31 & 0.9 & 1.5 & 3.72 & 108 & 60 & 1.768039 & 79.84045 & 1.866011 & 80.30473 \\
\hline 12 & 31 & 1.0 & 3 & -0.28 & 113 & 65 & 1.750658 & 81.48267 & 1.844729 & 81.12089 \\
\hline 13 & 31 & 1.1 & 4.5 & 0.72 & 118 & 45 & 1.733369 & 83.62648 & 1.842111 & 83.46803 \\
\hline 14 & 31 & 1.2 & -1.5 & 1.72 & 123 & 50 & 1.694157 & 79.17820 & 1.805450 & 84.58820 \\
\hline 15 & 31 & 1.3 & 0 & 2.72 & 103 & 55 & 1.755297 & 79.71979 & 1.843188 & 80.38825 \\
\hline 16 & 33 & 0.9 & 3 & 0.72 & 123 & 55 & 1.714483 & 80.93980 & 1.826645 & 83.84977 \\
\hline 17 & 33 & 1.0 & 4.5 & 1.72 & 103 & 60 & 1.806527 & 80.09542 & 1.924480 & 79.97257 \\
\hline 18 & 33 & 1.1 & -1.5 & 2.72 & 108 & 65 & 1.709343 & 80.47292 & 1.775109 & 78.72882 \\
\hline 19 & 33 & 1.2 & 0 & 3.72 & 113 & 45 & 1.681214 & 83.00076 & 1.762818 & 82.01911 \\
\hline 20 & 33 & 1.3 & 1.5 & -0.28 & 118 & 50 & 1.709789 & 83.69289 & 1.787212 & 82.95986 \\
\hline 21 & 35 & 0.9 & 4.5 & 2.72 & 113 & 50 & 1.754020 & 81.02556 & 1.871894 & 83.02352 \\
\hline 22 & 35 & 1.0 & -1.5 & 3.72 & 118 & 55 & 1.696652 & 82.71315 & 1.747687 & 82.21235 \\
\hline 23 & 35 & 1.1 & 0 & -0.28 & 123 & 60 & 1.707872 & 79.18577 & 1.805092 & 83.91313 \\
\hline 24 & 35 & 1.2 & 1.5 & 0.72 & 103 & 65 & 1.734484 & 80.00738 & 1.851991 & 79.62178 \\
\hline 25 & 35 & 1.3 & 3 & 1.72 & 108 & 45 & 1.746645 & 82.46514 & 1.808241 & 80.5998 \\
\hline
\end{tabular}

Table 4. Response averages and percentage contributions for area factor $17 \%$.

\begin{tabular}{cccccccc}
\hline \multirow{2}{*}{ Responses } & Influence level & \multicolumn{2}{c}{ Factors } & & & & \\
\cline { 3 - 8 } & & $Z$ & $t /(\mathrm{mm})$ & $\beta /\left(^{\circ}\right)$ & $\gamma /\left(^{\circ}\right)$ & $\alpha_{1} /\left(^{\circ}\right)$ & $\alpha_{2} /\left(^{\circ}\right)$ \\
\hline \multirow{2}{*}{ Stall torque ratio } & $K_{1}$ & 1.746891 & 1.739190 & 1.701710 & 1.732189 & 1.761371 & 1.718081 \\
$T r_{0}$ & $K_{2}$ & 1.744801 & 1.734095 & 1.718251 & 1.715639 & 1.740823 & 1.731195 \\
& $K_{3}$ & 1.740304 & 1.738950 & 1.735022 & 1.748072 & 1.725581 & 1.738535 \\
& $K_{4}$ & 1.724271 & 1.731284 & 1.755255 & 1.740356 & 1.730632 & 1.748955 \\
Peak efficiency & $K_{5}$ & 1.727934 & 1.740681 & 1.773964 & 1.747946 & 1.725794 & 1.747435 \\
$\eta^{*}$ /\% & $k_{1}$ & 80.44137 & 80.63080 & 80.64086 & 81.10389 & 79.98437 & 81.76468 \\
& $k_{2}$ & 80.76981 & 80.87810 & 80.72454 & 81.15638 & 80.86097 & 80.87282 \\
& $k_{3}$ & 80.76952 & 80.96230 & 80.93977 & 80.90281 & 81.55523 & 81.19159 \\
& $k_{4}$ & 81.64036 & 80.89070 & 81.21917 & 80.41166 & 82.49794 & 80.21414 \\
\hline
\end{tabular}


Table 5. Response averages and percentage contributions for area factor $20 \%$.

\begin{tabular}{|c|c|c|c|c|c|c|c|}
\hline \multirow{2}{*}{ Responses } & \multirow{2}{*}{ Influence level } & \multicolumn{6}{|l|}{ Factors } \\
\hline & & $z$ & $t /(\mathrm{mm})$ & $\beta /\left(^{\circ}\right)$ & $\gamma /\left(^{\circ}\right)$ & $\alpha_{1} /\left(^{\circ}\right)$ & $\alpha_{2} /\left(^{\circ}\right)$ \\
\hline \multirow{3}{*}{$\begin{array}{l}\text { Stall } \\
\text { torque } \\
\text { ratio }\end{array}$} & $K_{1}$ & 1.857101 & 1.841040 & 1.781985 & 1.828676 & 1.858806 & 1.808043 \\
\hline & $K_{2}$ & 1.836760 & 1.829005 & 1.810566 & 1.820702 & 1.831359 & 1.828002 \\
\hline & $K_{3}$ & 1.840298 & 1.830833 & 1.837948 & 1.847260 & 1.823719 & 1.836269 \\
\hline \multirow[t]{2}{*}{$T r_{0}$} & $K_{4}$ & 1.815253 & 1.839517 & 1.844994 & 1.837644 & 1.817728 & 1.849648 \\
\hline & $K_{5}$ & 1.816981 & 1.825997 & 1.890900 & 1.832111 & 1.834780 & 1.844429 \\
\hline \multirow{5}{*}{$\begin{array}{c}\text { Peak } \\
\text { efficiency } \eta^{*} \%\end{array}$} & $k_{1}$ & 80.30682 & 81.36937 & 80.93785 & 81.44385 & 79.50789 & 81.81686 \\
\hline & $k_{2}$ & 81.21795 & 81.58206 & 81.51928 & 81.54131 & 80.09317 & 81.94710 \\
\hline & $k_{3}$ & 81.97402 & 81.48846 & 81.93184 & 81.72097 & 81.81977 & 81.89025 \\
\hline & $k_{4}$ & 81.50603 & 81.68679 & 81.62348 & 81.62348 & 82.25771 & 81.26595 \\
\hline & $k_{5}$ & 81.87412 & 80.75227 & 81.26861 & 80.54932 & 83.20041 & 79.95878 \\
\hline
\end{tabular}

One other important aspect of the DOE method is the ability to calculate the percentage contribution of a geometric parameter to a specified performance characteristic. The percentage contributions are calculated from an analysis of variance that effectively measures how far the performance characteristic values for a specific geometry variable vary from the mean. The amount that the high and low parameter levels vary from the mean provides a measure of that parameter's influence on a particular performance characteristic. This is converted into a percentage value to provide a measure of the contribution relative to the other parameters. Again percentage contributions have been calculated for each area factor. A summary of the percentage contributions for stall torque ratio $T r_{0}$ and peak efficiency $\eta^{*}$ at area factors $17 \%$ and $20 \%$ is shown in Figure 12.

The percentage contributions provide a great deal of information regarding the importance of the various geometric factors of impeller. As shown in Figure 12 , exit angle $\alpha_{1}$ has the strongest effect on peak efficiency at both $17 \%$ and $20 \%$ area factors although this effect reduces for the stall torque ratio. It should be noted that while the peak efficiency contributions for the bias angle $\beta$ are relatively low, the contributions to the stall torque ratio at both area factors are surprisingly large. The inlet angle $\alpha_{2}$ and blade number $z$ show a lesser contribution while the blade thickness $t$ generally has a significantly lesser effect. It can be concluded that the inlet angle $\alpha_{2}$, bias angle $\beta$, and exit angle $\alpha_{1}$ exert the greatest influence on the overall performance of a torque converter.

The DOE array provides useful information in the form of the percentage contributions, but not provide information on interaction effects between the geometric parameters. Later, a CCD technique will be used to gauge the interactive effect among these three dominant factors. 


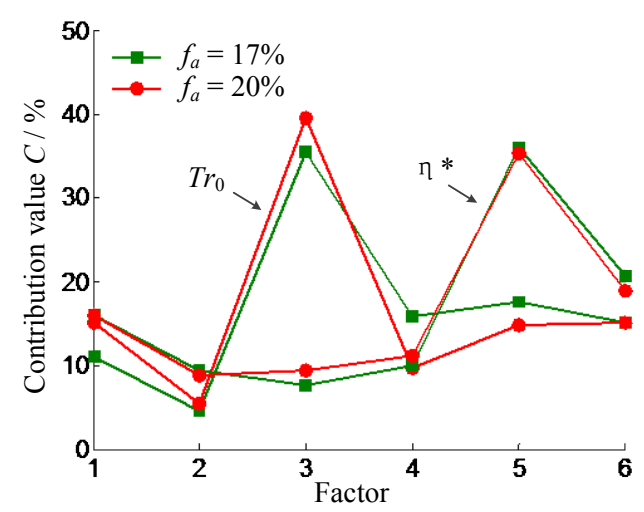

Figure 12. Percentage contributions of influence factors (1 - 6 correspond to $z, t, \beta, \gamma, \alpha_{1}$ and $\alpha_{2}$ respectively).

\section{Optimization Analysis}

\subsection{Central Composite Design (CCD)}

The CCD consists of a two-level full or fractional factorial design (corner points), an additional design (star points) and at least one point at the center of the design space (center points) (Figure 13). If the distance from the center of the design space to a factorial point is \pm 1 unit for each factor, the distance from the center of the design space to a star point is $\pm \alpha$ with $|\alpha|>1$. The $\alpha$ value equals to $\left(2^{m}\right)^{1 / 4}$, where $m$ is the number of factors [31] [32]. In the present study, $m$ equals to 3 so that the $\alpha$ value is 1.682. Therefore, each factor is studied in five different levels $(-1.682,-1,0,+1,+1.682)$, which is listed in Table 6 .

According to CCD, 15 torque converter cases should be modeled and their properties are presented in Table 7. It should be noted that nine points are considered for central points and two responses are considered for the optimization, stall torque ratio and peak efficiency. The corresponding calculation results for two area factors are presented in Figure 14 and Figure 15. Figure 14 reveals that case 4 has the maximum stall torque ratio, but it has a low peak efficiency and case 10 has the maximum peak efficiency. As seen in Figure 15, case 10 also has the best peak efficiency, but it has the minimum stall torque ratio and case 9 has the maximum stall torque ratio. So, an optimization study is needed which is performed using CCD technique in the present study.

\subsection{Evaluation and Optimization}

In CCD, a polynomial model with quadratic order is applied to responses (stall torque ratio and peak efficiency). $P$-value Probs are estimated to be 0.0024 and less than 0.0001 while R-squared values are 0.8002 and 0.9909 for $T r_{0}$ and $\eta^{*}$, respectively, for $20 \%$ area factor. For $17 \%$ area factor, $P$-values are also estimated to be less than 0.0001 while R-squared values are 0.9596 and 0.9957 for $T r_{0}$ and $\eta^{*}$, respectively, which are meaningful. By using the quadratic equation for the surfaces, the stall torque ratio and peak efficiency can be estimated by the following equations for different area factors. 


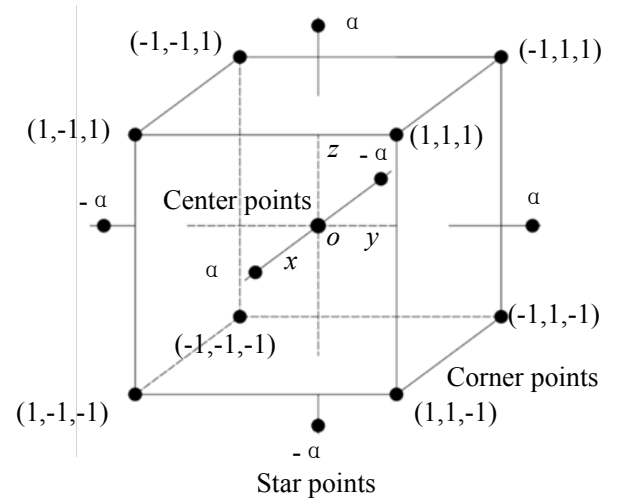

Figure 13. CCD design points.

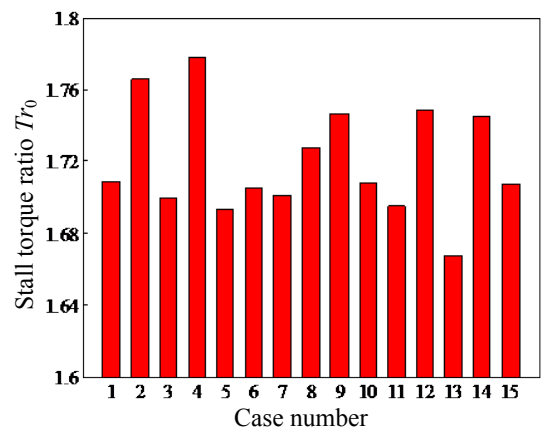

(a)

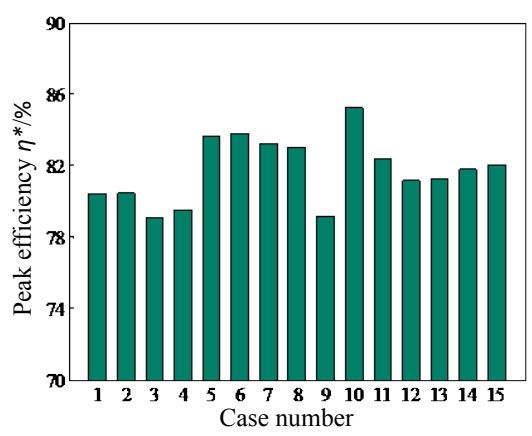

(b)

Figure 14. (a) Stall torque ratio and (b) peak efficiency for all designed cases at $17 \%$ area factor.

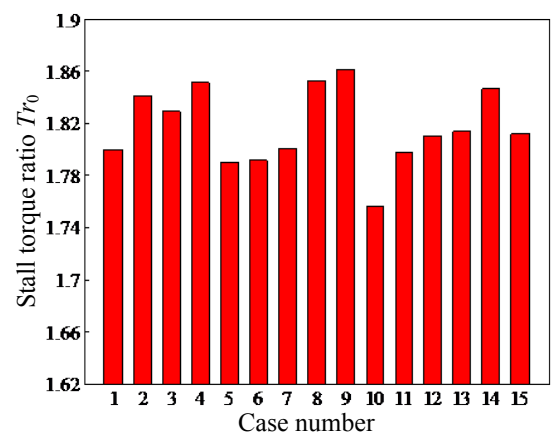

(a)

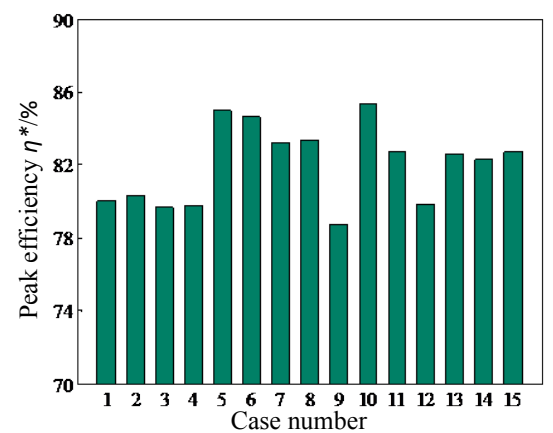

(b)

Figure 15. (a) Stall torque ratio and (b) peak efficiency for all designed cases at $20 \%$ area factor.

Table 6. Factors and levels in CCD.

\begin{tabular}{cccccc}
\hline Factors & Levels & & & & \\
& -1.682 & -1 & 0 & 1 & 1.682 \\
$\alpha_{1} /\left(^{\circ}\right)$ & 96.182 & 103 & 113 & 123 & 129.818 \\
$\alpha_{2} /\left(^{\circ}\right)$ & 33.182 & 40 & 50 & 60 & 66.818 \\
$\beta /\left(^{\circ}\right)$ & -3.3636 & -2 & 0 & 2 & 3.3636 \\
\hline
\end{tabular}


Table 7. Design matrix and results in CCD.

\begin{tabular}{cccc}
\hline & Factors & & \\
\cline { 2 - 4 } Case number & $\alpha_{1} /\left(^{\circ}\right)$ & $\alpha_{2} /\left(^{\circ}\right)$ & $\beta /\left(^{\circ}\right)$ \\
\hline 1 & 103 & 40 & -2 \\
3 & 103 & 40 & 2 \\
4 & 103 & 60 & -2 \\
5 & 103 & 60 & 2 \\
6 & 123 & 40 & -2 \\
7 & 123 & 40 & 2 \\
8 & 123 & 60 & -2 \\
9 & 123 & 60 & 2 \\
10 & 96.18 & 50 & 0 \\
11 & 129.82 & 50 & 0 \\
12 & 113 & 33.18 & 0 \\
13 & 113 & 66.82 & 0 \\
14 & 113 & 50 & -3.36 \\
15 & 113 & 50 & 3.36 \\
\hline & 113 & 50 & 0 \\
\hline
\end{tabular}

1) $17 \%$ area factor:

$$
\begin{aligned}
\operatorname{Tr}_{0}= & 3.142854-0.020606 \times \alpha_{1}-0.008621 \times \alpha_{2}+0.069109 \times \beta \\
& +0.000033 \times \alpha_{1} \times \alpha_{2}-0.000614 \times \alpha_{1} \times \beta+0.000228 \times \alpha_{2} \times \beta \\
& +0.000077634 \times \alpha_{1}^{2}+0.000057431 \times \alpha_{2}^{2}+0.000088982 \times \beta^{2} \\
\eta^{*}= & 70.576115+0.063839 \times \alpha_{1}-0.052123 \times \alpha_{2}+0.459299 \times \beta \\
& +0.001304 \times \alpha_{1} \times \alpha_{2}-0.003970 \times \alpha_{1} \times \beta+0.000718 \times \alpha_{2} \times \beta \\
& +0.000224 \times \alpha_{1}^{2}-0.001356 \times \alpha_{2}^{2}-0.053936 \times \beta^{2}
\end{aligned}
$$

2) $20 \%$ area factor:

$$
\begin{array}{rl}
\operatorname{Tr}_{0}=2 & .133640-0.003426 \times \alpha_{1}-0.001724 \times \alpha_{2}+0.003084 \times \beta \\
+ & 0.000040423 \times \alpha_{1} \times \alpha_{2}-0.000061050 \times \alpha_{1} \times \beta+0.000203 \times \alpha_{2} \times \beta \\
- & 0.000002332 \times \alpha_{1}^{2}-0.000018698 \times \alpha_{2}^{2}+0.001840 \times \beta^{2} \\
\eta^{*}= & 6.418795+0.844738 \times \alpha_{1}+0.751594 \times \alpha_{2}+0.373003 \times \beta \\
& -0.002840 \times \alpha_{1} \times \alpha_{2}-0.004281 \times \alpha_{1} \times \beta+0.001974 \times \alpha_{2} \times \beta \\
& -0.002217 \times \alpha_{1}^{2}-0.004945 \times \alpha_{2}^{2}-0.017527 \times \beta^{2}
\end{array}
$$

By applying the above formula one can approximate the stall torque ratio and peak efficiency for all non-simulated cases.

As mentioned above, the interaction of each parameter with other parameters should be considered at the same time on stall torque ratio and peak efficiency. Therefore, the response surfaces are presented in Figure 16 and Figure 17 for each area factor, respectively, to show this interaction on $T r_{0}$ and $\eta^{*}$. These 
figures show the interaction between the three parameters for the optimized design. An increase in bias angle $\beta$ and inlet angle $\alpha_{2}$ together with an decrease in exit angle $\alpha_{1}$ yield higher stall torque ratio amounts although the effect of bias angle is more sensible than inlet angle and exit angle due to its high slope in the surface in Figure 16(a), Figure 16(b), Figure 17(a) and Figure 17(b). As an important outcome, exit angle has the most significant effect on peak efficiency, while bias angle and inlet angle may have optimum values that maximize the peak efficiency (Figure 16(c), Figure 16(d), Figure 17(c), and Figure $17(\mathrm{~d})$ ). It is of note that the minimum value of peak efficiency at $20 \%$ area factor is lower than that at $17 \%$ area factor as shown in Figure 16(c) and Figure $17(\mathrm{c})$. This phenomenon can be explained by the fact that the curvature of the core increases with the increase of flow area of a torque converter, which may result in larger flow losses.

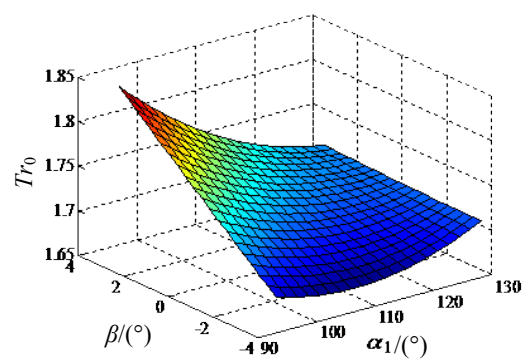

(a)

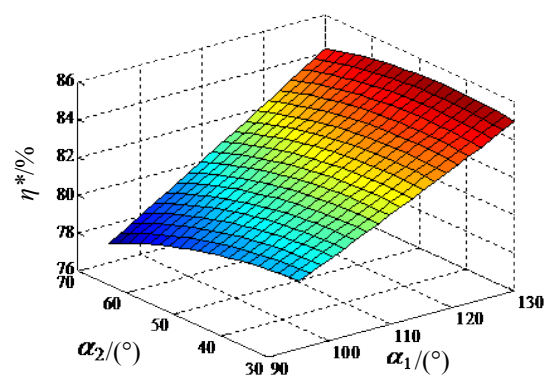

(c)

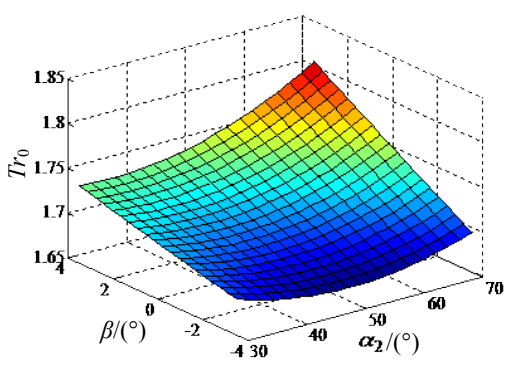

(b)

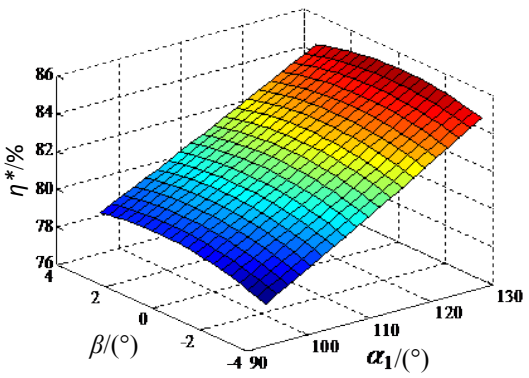

(d)

Figure 16. Response surface of stall torque ratio and peak efficiency for optimization at $17 \%$ area factor. (a) Exit angle and bias angle, (b) inlet angle and bias angle, (c) inlet angle and exit angle, and (d) exit angle and bias angle.

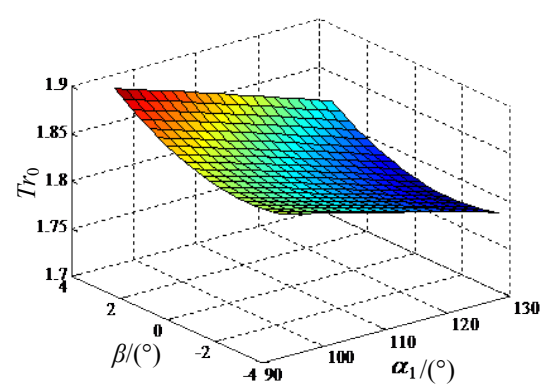

(a)

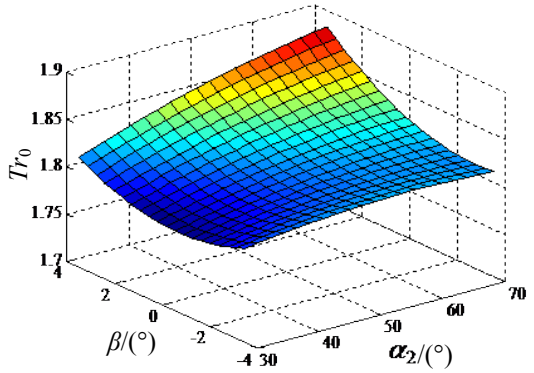

(b) 


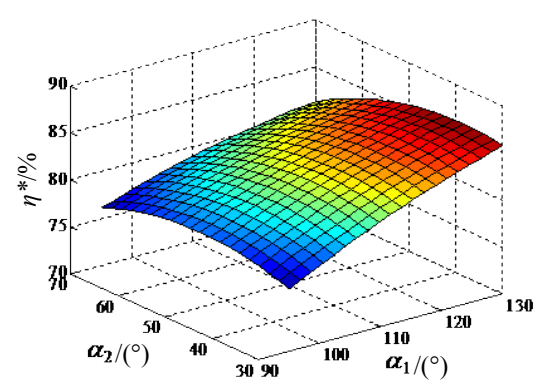

(c)

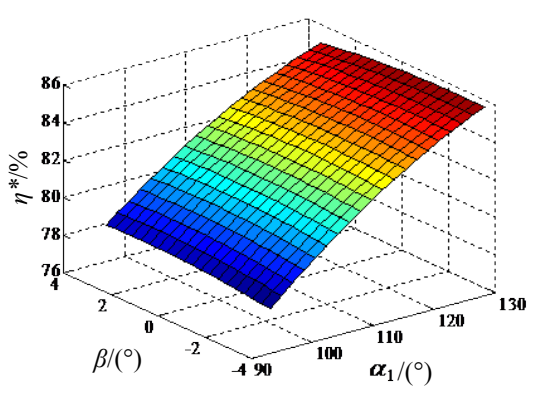

(d)

Figure 17. Response surface of stall torque ratio and peak efficiency for optimization at $20 \%$ area factor. (a) Exit angle and bias angle, (b) inlet angle and bias angle, (c) inlet angle and exit angle, and (d) exit angle and bias angle.

With CCD, optimization is based on a parameter called "desirability". Desirability is an objective function ranging from 0.0 outside of the limits to 1.0 at the goal. The numerical optimization finds a point that maximizes the desirability function. The characteristics of the goal may be altered by adjusting the weight or importance. For several responses and factors, all goals get combined into one desirability function [23]. In this paper, two responses are defined as stall torque ratio and peak efficiency. The goal of optimization is to find a set of conditions that meet all the goals, not to get a desirability value of 1.0. Desirability reflects the preferred ranges for each response $\left(d_{i}^{\prime}\right)$. The simultaneous objective function is a geometric mean of all transformed responses:

$$
D^{\prime}=\left(d_{1}^{\prime} \times d_{2}^{\prime} \times \cdots \times d_{n}^{\prime}\right)^{\frac{1}{n}}=\left(\prod_{i=1}^{n} d_{i}^{\prime}\right)^{\frac{1}{n}}
$$

where $n$ is the number of responses in the measure (in this case, $n=2$ ). If any of the responses or factors fall outside their desirability range, the overall function becomes zero. For simultaneous optimization, each response must have a low and high value assigned to each goal. In this study, the goal parameter used is "maximum" (for both stall torque ratio and peak efficiency) as follows:

$$
\begin{array}{lcrl}
d_{i}^{\prime} & =0 & Y_{i} & \leq \operatorname{Low}_{i} \\
d_{i}^{\prime} & =\left[\left(Y_{i}-\operatorname{Low}_{i}\right) /\left(\operatorname{High}_{i}-\operatorname{Low}_{i}\right)\right]^{w t_{i}}, & \operatorname{Low}_{i} & <Y_{i}<\operatorname{High}_{i} \\
d_{i}^{\prime} & =1 & Y_{i} & \geq \operatorname{High}_{i}
\end{array}
$$

where $Y_{i}$ is the $i$ th response value and $w t$ is the weight of that response. Weight adds emphasis to the goal. A weight greater than 1 (maximum weight is 10), emphasizes the goal and less than 1 (minimum weight is 0.1 ), deemphasizes the goal. In this paper, two responses are defined, the weights will be determined according to the designer's performance demand.

After optimization analysis by above surface formula, CCD proposes three optimized cases for each area factor (Table 8). Optimized cases 1 and 4 have the maximum stall torque ratio while optimized cases 2 and 5 have the best peak efficiency. Optimized cases 3 and 6 have the largest desirability when the weights of responses are considered equal. It is clear that torque converters with $20 \%$ area 
factor have better performance characteristics than torque converters with $17 \%$ area factor.

In the present study, optimized case 6 is selected as the final optimized case which is designed and calculated. Table 9 compares the theoretical and calculation results. The CFD calculation results at the optimum parameter combination confirm the effectiveness of the response surface model for optimum design parameters. Compared to the original model, the stall torque ratio and peak efficiency of the optimized one have increased by $1.62 \%$ and $1.1 \%$, respectively. Figure 18 shows the performance comparison of the optimized design with the original one which illustrates the improvement of performance.

\section{Conclusions}

A new parametric design method of the impeller for an automotive torque converter has been used to conduct a parametric study covering 11 geometric parameters. The 11 geometric parameters can be represented by 6 design parameters including the impeller blade number $z$, blade thickness $t$, bias angle $\beta$, scroll angle $\gamma$, exit angle $\alpha_{1}$ and inlet angle $\alpha_{2}$.

Table 8. Optimized cases proposed by CCD.

\begin{tabular}{crrrccc}
\hline No. & $f_{\mathrm{a}}$ & $\alpha_{1} /\left(^{\circ}\right)$ & $\alpha_{2} /\left(^{\circ}\right)$ & $\beta /\left(^{\circ}\right)$ & Predicted $\operatorname{Tr}_{0}$ & Predicted $\eta^{*} \%$ \\
\hline 1 & $17 \%$ & 96.180 & 33.180 & 3.36 & 1.8232 & 79.4588 \\
2 & $17 \%$ & 129.82 & 43.142 & -0.233 & 1.6985 & 85.1725 \\
3 & $17 \%$ & 97.771 & 33.180 & 3.36 & 1.8129 & 79.6771 \\
4 & $20 \%$ & 96.180 & 66.820 & 3.36 & 1.9006 & 77.1628 \\
5 & $20 \%$ & 129.82 & 38.104 & -3.069 & 1.7651 & 86.2945 \\
6 & $20 \%$ & 122.57 & 54.098 & 3.36 & 1.8416 & 83.6593
\end{tabular}

Table 9. Comparison of the calculation and CCD proposed values for optimized case 6.

\begin{tabular}{ccc}
\hline Responses & Calculation data & Predicted by CCD \\
\hline$r_{0}$ & 1.841955 & 1.84160 \\
$\eta^{*} \%$ & 83.76895 & 83.6593
\end{tabular}

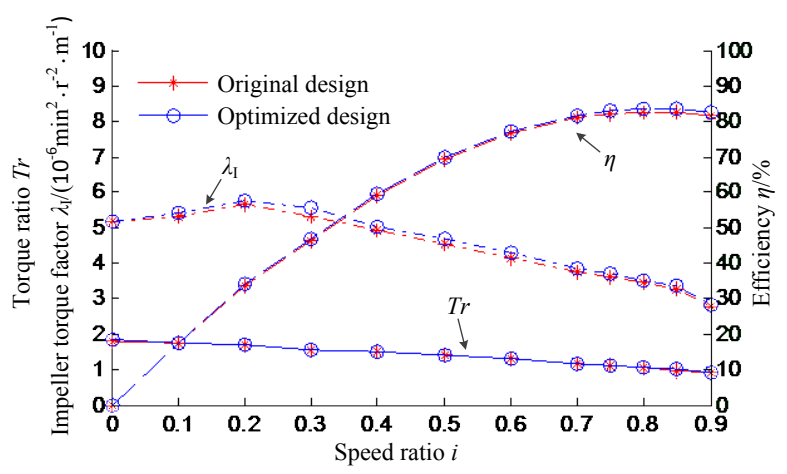

Figure 18. Performance comparison of the optimized design with the original model. 
An $L_{25}\left[5^{6}\right]$ DOE array has been successfully constructed for two responses including stall torque ratio and peak efficiency. The analysis of the array identified the dominant geometrical influences on the performance of the torque converter. In general, the impeller exit angle $\alpha_{1}$, inlet angle $\alpha_{2}$ and bias angle $\beta$ are the three strongest influences on the overall performance, with two area factors $(17 \%$ and $20 \%)$ considered.

CCD method has been employed to investigate the interactive effect among the impeller inlet angle, exit angle and bias angle. Predictive equations are presented that can identify expected performance at specific arrangements different from those analyzed. Results show that larger impeller bias angle and inlet angle together with smaller exit angle bring about an increase of the stall torque ratio while a larger exit angle is favorable to increase the peak efficiency. A final optimized design of impeller is obtained based on desirability function approach together with the predictive equations. Compared with the original model, the stall torque ratio and peak efficiency of the optimized model are increased by $1.62 \%$ and $1.1 \%$, respectively.

Performance prediction models with more prediction accuracy for a torque converter can be used as a further research direction.

\section{Conflicts of Interest}

The authors declare no conflicts of interest regarding the publication of this paper.

\section{References}

[1] Song, K., Kim, K., Park, J.I., et al. (2008) Development of the Integrated Process for Torque Converter Design and Analysis. SAE Technical Paper. https://doi.org/10.4271/2008-01-0785

[2] Dong, Y. and Lakshminarayana, B. (2001) Rotating Probe Measurements of the Pump Passage Flow Field in an Automotive Torque Converter. Journal of Fluids Engineering, 123, 81-91. https://doi.org/10.1115/1.1341202

[3] Gallimore, S.J. (1999) Axial Flow Compressor Design. Proceedings of the Institution of Mechanical Engineers, Part C: Journal of Mechanical Engineering Science, 213, 437-449. https://doi.org/10.1243/0954406991522680

[4] Rutter, R., Sheth, K. and O’Bryan, R. (2013) Numerical Flow Simulation and Validation of an Electrical Submersible Pump. ASME 2013 Fluids Engineering Division Summer Meeting, Incline Village, 7-11 July 2013, V01AT03A005.

[5] Zhao, B., Wang, Y., Chen, H., et al. (2015) Hydraulic Optimization of a Double-Channel Pump's Impeller Based on Multi-Objective Genetic Algorithm. Chinese Journal of Mechanical Engineering, 28, 634-640. https://doi.org/10.3901/CJME.2015.0116.016

[6] Shojaeefard, M.H., Tahani, M., Ehghaghi, M.B., et al. (2012) Numerical Study of the Effects of Some Geometric Characteristics of a Centrifugal Pump Impeller That Pumps a Viscous Fluid. Computers \& Fluids, 60, 61-70. https://doi.org/10.1016/j.compfluid.2012.02.028

[7] Bellary, S.A.I., Adhav, R., Siddique, M.H., et al. (2016) Application of Computational Fluid Dynamics and Surrogate-Coupled Evolutionary Computing to Enhance 
Centrifugal-Pump Performance. Engineering Applications of Computational Fluid, 10, 171-181. https://doi.org/10.1080/19942060.2015.1128359

[8] Hur, N., Moshfeghi, M. and Lee, W. (2016) Flow and Performance Analyses of a Partially-Charged Water Retarder. Computers \& Fluids, 164, 18-26.

[9] Yan, P. and Wu, G.Q. (2008) System for Torque Converter Design and Analysis Based on CAD/CFD Integrated Platform. Chinese Journal of Mechanical Engineering, 21, 35-39. https://doi.org/10.3901/CJME.2008.04.035

[10] Dong, Y., Korivi, V., Attibele, P., et al. (2002) Torque Converter CFD Engineering Part I: Torque Ratio and K Factor Improvement through Stator Modifications. SAE Technical Paper. https://doi.org/10.4271/2002-01-0883

[11] Wu, G.Q. and Wang, L.J. (2016) Application of Dual-Blade Stator to Low-Speed Ratio Performance Improvement of Torque Converters. Chinese Journal of Mechanical Engineering, 29, 293-300. https://doi.org/10.3901/CJME.2015.1218.151

[12] Kubo, M. and Ejiri, E. (1998) A Loss Analysis Design Approach to Improving Torque Converter Performance. SAE Technical Paper. https://doi.org/10.4271/981100

[13] Shin, S., Bae, I., Joo, I.S., et al. (2000) The Effect of Blade Geometry on the Performance of an Automotive Torque Converter. FISITA World Automotive Congress, Seoul, Koreo, 12-15 June 2000, 1-7.

[14] Shin, S., Kim, K.J., Kim, D.J., et al. (2002) The Effect of Reactor Blade Geometry on the Performance of an Automotive Torque Converter. SAE Technical Paper.

https://doi.org/10.4271/2002-01-0885

[15] Shin, S., Lee, B.C., Hong, J.H., et al. (2003) Performance Improvement Using a Slotted Stator of an Automotive Torque Converter. SAE Technical Paper. https://doi.org/10.4271/2003-01-0247

[16] Wakale, A.B., Venkatasubbaiah, K. and Sahu, K.C. (2015) A Parametric Study of Buoyancy-Driven Flow of Two-Immiscible Fluids in a Differentially Heated Inclined Channel. Computers \& Fluids, 117, 54-61. https://doi.org/10.1016/j.compfluid.2015.04.021

[17] Park, S., Yang, J. and Rhee, S.H. (2017) Parametric Study on Ship's Exhaust-Gas Behavior Using Computational Fluid Dynamics. Engineering Applications of Computational Fluid, 11, 159-171. https://doi.org/10.1080/19942060.2016.1260057

[18] Ayli, E., Celebioglu, K. and Aradag, S. (2016) Determination and Generalization of the Effects of Design Parameters on Francis Turbine Runner Performance. Engineering Applications of Computational Fluid, 10, 545-564. https://doi.org/10.1080/19942060.2016.1213664

[19] Park, J., Cha, H., Song, S., et al. (2011) A Numerical Study of a Methane-Fueled Gas Engine Generator with Addition of Hydrogen Using Cycle Simulation and DOE Method. International Journal of Hydrogen Energy, 36, 5153-5162. https://doi.org/10.1016/j.ijhydene.2011.01.019

[20] Wu, D., Yuan, S., Ren, Y., et al. (2016) CFD Investigation of the Influence of Volute Geometrical Variations on Hydrodynamic Characteristics of Circulator Pump. Chinese Journal of Mechanical Engineering, 29, 315-324. https://doi.org/10.3901/CJME.2015.1224.154

[21] Taghavifar, H., Jafarmadar, S., Taghavifar, H., et al. (2016) Application of DoE Evaluation to Introduce the Optimum Injection Strategy-Chamber Geometry of Diesel Engine Using Surrogate Epsilon-SVR. Applied Thermal Engineering, 106, 56-66. https://doi.org/10.1016/j.applthermaleng.2016.05.194

[22] Sagbas, A. (2011) Analysis and Optimization of Surface Roughness in the Ball Bur- 
nishing Process Using Response Surface Methodology and Desirabilty Function. Advances in Engineering Software, 42, 992-998. https://doi.org/10.1016/j.advengsoft.2011.05.021

[23] Hatami, M., Cuijpers, M.C.M. and Boot, M.D. (2015) Experimental Optimization of the Vanes Geometry for a Variable Geometry Turbocharger (VGT) Using a Design of Experiment (DoE) Approach. Energy Conversion and Management, 106, 1057-1070. https://doi.org/10.1016/j.enconman.2015.10.040

[24] Kęsy, A. and Kądziela, A. (2011) Construction Optimization of Hydrodynamic Torque Converter with Application of Genetic Algorithm. Archives of Civil and Mechanical Engineering, 11, 905-920. https://doi.org/10.1016/S1644-9665(12)60086-7

[25] Wu, G.Q. and Wang, L.J. (2012) Performance Optimization of Torque Converters Based on Modified 1D Flow Model. Journal of Donghua University, 29, 380-384.

[26] Wu, G.Q. and Wang, L.J. (2015) Multi-Objective Optimization Employing Genetic Algorithm for the Torque Converter with Dual-Blade Stator. SAE Technical Paper. https://doi.org/10.4271/2015-01-1119

[27] Aslan, N. (2008) Application of Response Surface Methodology and Central Composite Rotatable Design for Modeling and Optimization of a Multi-Gravity Separator for Chromite Concentration. Powder Technology, 185, 80-86. https://doi.org/10.1016/j.powtec.2007.10.002

[28] Hatami, M., Ganji, D.D. and Gorji-Bandpy, M. (2015) Experimental and Thermodynamical Analyses of the Diesel Exhaust Vortex Generator Heat Exchanger for Optimizing Its Operating Condition. Applied Thermal Engineering, 75, 580-591. https://doi.org/10.1016/j.applthermaleng.2014.09.058

[29] Hatami, M., Ganji, D.D. and Gorji-Bandpy, M. (2015) Experimental and Numerical Analysis of the Optimized Finned-Tube Heat Exchanger for OM314 Diesel Exhaust Energy Recovery. Energy Conversion and Management, 97, 26-41. https://doi.org/10.1016/j.enconman.2015.03.032

[30] Spence, R. and Amaral-Teixeira, J. (2009) A CFD Parametric Study of Geometrical Variations on the Pressure Pulsations and Performance Characteristics of a Centrifugal Pump. Computers \& Fluids, 38, 1243-1257. https://doi.org/10.1016/j.compfluid.2008.11.013

[31] Sun, L. and Zhang, C.L. (2014) Evaluation of Elliptical Finned-Tube Heat Exchanger Performance Using CFD and Response Surface Methodology. International Journal of Thermal Sciences, 75, 45-53. https://doi.org/10.1016/j.ijthermalsci.2013.07.021

[32] Hatami, M., Jafaryar, M., Ganji, D.D., et al. (2014) Optimization of Finned-Tube Heat Exchangers for Diesel Exhaust Waste Heat Recovery Using CFD and CCD Techniques. International Communications in Heat and Mass, 57, 254-263. https://doi.org/10.1016/j.icheatmasstransfer.2014.08.015 